\title{
Comparing Time Present with Time Future: Discounting in the Stern Review
}

\author{
Dennis Rose
}

\section{Introduction}

What actions should we, as a subset of world citizenry, be contemplating now in response to the likely effects of climate change? That is the fundamental question posed by the Stern Review. As is the case with most large questions, our individual and collective responses are conditioned by our systems of values, by the institutions within which we work, by uncertainties about the facts and by the intellectual frameworks that help structure our understanding of reality.

Diverse values and imperfect institutions accepted, our immediate needs are for greater clarity and broader appreciation of the emerging facts and for continuing dialogue on how we should respond to them. The Stern Review paints a sombre picture. Energy-related $\mathrm{CO}_{2}$ emissions are now some five times the level prevailing in the 1950s, at which point they were roughly in balance with the globe's annual capacity to re-absorb them. The resulting build-up in atmospheric greenhouse gas concentrations will continue until such time as annual emissions are radically reduced, and will cause significant lifts in global temperatures, of uncertain extent and over a long period. Although warming temperatures will have some beneficial effects, the adverse effects will increasingly predominate at higher temperatures.

The Stern team reviews what is known about the range and likely scale of such effects and adds its own contribution to attempts to model and quantify the annual economic impact of climate change over the horizon to the year 2200. Faced with the uncertainties inherent in forecasting, Stern uses probabilistic modelling to assess the range and associated mean values for annual damage under several scenarios.

Stern also assesses the possible cost of policies designed to reduce levels of greenhouse gas emissions below the levels that would prevail under 'business as usual' conditions. The review surveys attempts to estimate the cost of a wide range of initiatives to reduce greenhouse gas emissions using available technologies and, assuming that these set outer limits on achievable costs, concludes that continuing expenditures equal to $1 \%$ of global GDP have the potential to limit greenhouse gas concentrations to acceptable levels.

Stern's estimates of the costs of climate damage and of policies designed to reduce such damage have had a mixed reception (e.g. Carter et al., 2006). Acknowledging the uncertainties in all such projections, and that we are all, Stern and critics included, exposed to error and bias, the likely gravity of the emerging situation and the long leads and lags in the climate system make it imperative to essay such estimates. We have a collective interest in building as clear a picture as we can of the consequences of failing to act and of the costs of action. If we had perfect foreknowledge, we would be able to call up the required time series off the shelf. Lacking that, we can be grateful that Stern has pushed the limits thus far. Accepting these, or more refined future estimates of the costs of climate damage and of policies to reduce greenhouse gas emissions, the problem is to compare them.

\section{Discounting}

The costs of climate change will persist long into the future, whilst policies to limit climate change require spending now and over coming decades. How do we, as individuals and as a community, compare costs incurred today with benefits (in the form of reduced costs) occurring far in the future?

The standard tool is discounting. Working on the basis that a given quantum of anything at some point in the future is less valuable than the same quantum in our hands now, it is usual to discount the value of future benefits and costs. At what rate should we 
discount the future? In some situations, as when borrowing for house purchase, an obvious rate is that at which we borrow. For public investment the discount rate is a given, with the rate being set by the relevant controlling authority.

The most commonly quoted New Zealand rate for public project appraisal is $10 \%$, as prescribed by Treasury and by Transfund for roading projects. The problem with this rate for assessing policies designed to mitigate climate change is that $10 \%$ focuses attention very much on the near term and effectively ignores the longer run.

Using Transfund's rule, which also limits the time horizon to 25 years, a constant stream of benefits accruing at $\$ 1$ million per annum will sum to $\$ 9.07$ million. Even if we extend our horizon indefinitely, the discounted benefits will never exceed $\$ 10$ million. The $10 \%$ rule effectively removes all but a few of the costs and benefits accruing more than 25 years out from consideration and is thus inappropriate, when our primary focus is on longer-term issues.

Dissatisfaction with the implications of such high discount rates, which were long the international norm, has led to significant changes in practice in some countries. A leading example is the United Kingdom, whose 2002 'Green Book' prescribes a 3.5\% discount rate for the first 75 years of a project's life, with declining rates thereafter.

The Stern Review's extensive discussion on discounting, which many have interpreted as advocating a radical lowering of the discount rate to $0.1 \%$, has caused sharp controversy.

\section{Determining a discount rate}

Discount rate theory is, in any event, an active and contentious field. Any proposed discount rate depends on some underlying theoretical structure identifying the relevant components and an appeal to empirical evidence or to first principles as a guide to their magnitude.

Suppose we have reasonable estimates of the time streams of costs and benefits associated with proceeding down a particular policy path. Then, the net present value of that policy path can be assessed as

$$
N P V=\sum_{t}^{T} \frac{\left(b_{t}-c_{t}\right)}{(1+r)^{t}}
$$

i.e., as the sum of the project benefits, $b$, less the costs, $c$, accumulated over the relevant time period and discounted at the rate $r$ (e.g., for a 3\% discount rate $1+r=1.03)$.

The discount factor $r$ is variously derived and with some variation in symbolism, but the following equation brings together the major elements:

$r=\delta+\eta g+\phi \beta$

In this equation $\delta$ (delta) is a measure of pure time preference. We discuss it further below.

The second component, $\eta g$, deals with the likelihood that per capita consumption will grow over time so that future consumption will be relatively plentiful and will have lower utility. The first element, $\eta$ (eta), measures the responsiveness of utility to consumption and $g$ measures the rate of growth of per capita consumption.

Taken together, these two components, i.e. $(\delta+\eta g$ comprise the social time preference rate, which is evaluated in the UK Green Book at 3.5\%. The social time preference rate depends upon the perceived utility of consumption at different points in time and is risk-free.

The final component, $\phi \beta$, adds risk to the picture. The first element, $\phi$ (phi), measures the price of risk (approximated by the difference between some measure of average market returns and the risk-free rate), whilst $\beta$ (beta) measures the quantity of risk, usually measured as the likely variability, and hence riskiness, of the contemplated investment type, expressed relative to the variability and riskiness of a wider reference market.

Taken as a whole, equation 2 provides one measure of the social opportunity cost of capital (often further extended to take account of tax impacts), which stands as a competing discounting norm to the rate of social time preference. The appeal of the opportunity cost measure is that it focuses on the returns that might be secured from investing a block of funds in the private marketplace rather than in a particular public project. Critics of this approach, who argue for use of the alternative, social time preference rate, note that the risks surrounding public sector projects are fundamentally different from those embodied in equity markets (Spackman, 2004; Quiggin, 2005) and that in an open international economy the opportunity cost of public investments can be approximated by the real cost of public borrowing (Lind, 1990). 
In my view, risk is generally better modelled, within public sector project appraisal, as an element within the cost and benefit streams than as an add-on within the discount rate. For our purposes, we can leave that issue aside. The questions raised by the Stern Review relate to pure time preference, $\delta$, and the social time preference rate, $(\delta+\eta g)$.

\section{Discount rates in the Stern Review}

Chapter 2 of the Stern Review, a technical annex and supporting papers by John Broome and Cameron Hepburn, deal with discounting. The authors argue that whilst standard cost-benefit appraisals are appropriate for analysing marginal projects within stable frameworks, they are inappropriate for comparison of very different economic trajectories involving very long-term and large inter-generational impacts, such as are involved in contemplating climate change.

For example, as we have seen, the social time preference rate, $(\delta+\eta g)$, is itself a function of the rate of growth in per capita consumption, $g$. If we are comparing long-run scenarios in which the rate of growth in consumption is itself sensitive to climatic outcomes, then the appropriate discount rate is scenario specific. Furthermore, stable discount rates are predicated on stable future growth paths. If we expect the rate of growth in consumption to vary through time, then the appropriate discount rate will depend on the time period chosen. Declining per capita consumption could even lead to negative discount rates. Uncertainty about future growth paths also creates a case for discount rates that decline through time.

More fundamentally, the authors ask what are the ethical bases on which we make judgements about the welfare of distant generations. Drawing on the reasoning of a long line of writers, including Ramsey, Pigou and Solow, they argue that we have very little basis for valuing the welfare of future generations as inherently different from that of our own:

the current generation does not have the right to consume or damage the environment and the planet in a way that gives its successor worse life chances than it itself enjoyed,

and conclude that

the only sound ethical basis for placing less value on the utility [as opposed to consumption] of future generations [is] the uncertainty over whether or not the world will exist, or whether those generations will all be present. (Stern, pp.42, 45)

Quantification of the uncertainty of the future existence of the human race is not simple, but Stern argues that a value of $0.1 \%$ is appropriate for $\delta$, the parameter dealing with pure time preference. Recall that this is only one element within the social rate of time preference. The authors emphasise that using a low value for $\delta$ does not imply a low discount rate: 'Growing consumption is a reason for discounting' (Stern, p.48).

It is at this point that confusion has arisen. Much of the review's algebra does indeed suggest that $\delta$ is used as the discount rate, rather than as just one component in determining that rate (e.g., Stern, Box 6.3). However that may be, material subsequently posted on the UK Treasury website, including the January 2007 paper 'Frequently asked questions', reports that the discount rate used in the modelling exercise is sensitive to the rate of growth in per capita consumption and the marginal utility of consumption. Documentation for the PAGE2002 model that was used for the cost of climate damage scenarios shows that the default discount rate equation is similarly comprehensive (Alberth and Hope, 2005, p.15).

On this basis, it would appear that the discount rate used by Stern to convert future time streams of climate costs to present values was around $1.4 \%$. Recalling our social time preference rate equation, $\rho=\delta+\eta g$, we have $\delta=0.1, \eta=1.0$, and $g=1.3$ (which is the average per capita consumption growth rate as per PAGE2002's baseline projection as given in Stern's Box 6.3). That is, we have $0.1+1 \cdot 0^{*} 1.3=1.4 \%$. By way of contrast, the UK Green Book uses $\delta=1.5$ (covering both pure time preference and risk of catastrophe), $\eta=1.0$, and $g=2.0$, leading to a discount rate of $3.5 \%$. Quite clearly we are dealing with uncertain parameters and the Stern Review could usefully have reported the sensitivity of its results to variation in discount rates.

\section{Cost scenarios in the Stern Review}

Part II of the Stern Review assesses the impacts of climate change on growth and development and estimates the likely economic costs associated with temperature increases resulting from increases in greenhouse gas concentrations. 
Modelling work undertaken by the review suggests that the risks and costs of climate change over the next two centuries could be equivalent to an average reduction in global per capita consumption of at least 5\% now and forever. The estimated damages would be much higher if non-market impacts, the possibility of greater climate sensitivity, and distributional issues were also taken into account. (Stern, p.55)

Stern frequently acknowledges that all such estimates are surrounded by great uncertainties. The projections have been challenged and need to be critically reviewed, but let us accept them as they are so that we can explore their implications.

Centrally we have two sets of forecasts: first, projections of the likely cost of climate change over the next 200 years, expressed as reductions in GDP as compared with the levels that might be assumed to arise under business as usual. Secondly, we have a set of projections of the possible cost of mitigation programmes designed to limit the extent of climate change.

The climate cost projections are generated through a Monte Carlo-type model in which all the more important uncertainties are represented by probability distributions quantifying the range of possible outcomes. The model, primed with some necessary exogenous assumptions, including rates of growth in population and per capita consumption, is then used to generate a sequence of runs in which, at each decision node, a random choice is made from amongst the relevant probability distributions. The results of 1,000 such runs are then summarised by their mean values and by the fifth and 95th percentiles. Table 1 summarises Stern estimates of mean losses in income per capita, expressed as percentages of GDP, under two scenarios over the period to the year 2200 . The numbers are read from Figure 6.5 at page 157 of the review and are approximate.

Three features stand out. First, the initial impacts of climate change are not all that great, amounting to reductions in per capita income of well under $1 \%$ in
2050. The Stern models assume continuing increases in per capita income at $1.3 \%$ per annum, so that average per capita income is posited to be some $90 \%$ higher in 2050 than in 2000. Against this yardstick the early losses seem small.

Secondly, the forecast costs of climate change increase strongly during the 22nd century, reflecting increases in greenhouse gas concentrations that will continue until such time as global emissions are brought back into balance with earth's re-absorptive capacity.

Thirdly, the forecast costs of climate change increase in scenarios that assume higher temperature change, and increase further as the modelled range of possible effects increases.

The model runs incorporate constant rates of growth in population and per capita income. Given the scale of impacts that are being forecast, this assumption becomes increasingly more tenuous as time lengthens. Ideally, as the review acknowledges, these two variables should be forecast endogenously, within the model.

Note, in this connection, that much depends on the underlying rate of technical progress, particularly as it relates to the balance between output and environmental quality. Stern posits a production function where output is a function of capital, labour and environmental quality, $Y(t)=F(K, L, E)$ (p.124). Given any level of technical innovation reducing environmental impact per unit of GDP, there is the potential for a parallel rate of growth in real incomes without damage to the environment. The twin challenges are to secure a sufficient level of innovation and secondly to constrain the rate of growth in real consumption within that limit.

\section{Testing sensitivity to discount rate}

As noted earlier, Stern concludes that continuing expenditures equal to $1 \%$ of global GDP have the potential to limit greenhouse gas concentrations to acceptable levels. I use this judgement, along with the annual damage cost estimates read from Stern's Figure 6.5 as input to a 200-year cost-benefit analysis which enables us to assess the sensitivity of comparisons

Table 1: Losses in income per capita, \% of GDP

\begin{tabular}{|l|l|l|l|l|}
\hline & $\mathbf{2 0 5 0}$ & $\mathbf{2 1 0 0}$ & $\mathbf{2 1 5 0}$ & $\mathbf{2 2 0 0}$ \\
\hline Baseline & 0.2 & 0.9 & 3.1 & 5.3 \\
\hline High Climate & 0.5 & 2.9 & 8.3 & 13.8 \\
\hline
\end{tabular}


Table 2: Ratios of discounted climate and mitigation costs

\begin{tabular}{|l|l|l|l|l|l|}
\hline Discount rate & $0.1 \%$ & $1.4 \%$ & Green Book & $5 \%$ & $10 \%$ \\
\hline Baseline & 3.26 & 2.15 & 1.18 & 0.21 & 0.05 \\
\hline High Climate & 8.67 & 5.80 & 3.19 & 0.58 & 0.12 \\
\hline
\end{tabular}

Source: Author estimates. A supporting workbook is available from dennis.rose@clear.net.nz.

of these costs and benefits to differing discount rate assumptions.

Table 2 reports ratios of discounted time streams of climate costs and mitigation costs as projected by Stern. Ratios greater than 1.0 imply that the discounted present value of mitigation programmes is less than the similarly discounted value of the costs of climate damage resulting from business as usual. A ratio greater than 1.0 implies that, at the quoted discount rate, it would be sensible for society to undertake the mitigation programme rather than suffer the consequences of climate change.

As can be seen, the resulting ratios are greater than unity, over a 200 -year time span, not only at a pure time preference discount rate of $0.1 \%$ and at the $1.4 \%$ rate used by Stern, but also at UK Treasury Green Book rates. But discount rates of $5 \%$ and $10 \%$ yield ratios less than unity.

Summing up to this point, the Stern Review projections of climate damage and mitigation costs establish a prima facie case for mitigation policies along the lines proposed not only when evaluated in terms of pure time preference, but also when discounted at rates corresponding to more commonly accepted values of social time preference rates.

\section{The costs of business-as-usual climate change 'now and forever'}

When reporting modelled estimates of the costs of climate change, the Stern Review frequently refers to costs equivalent to some percentage of global per capita consumption 'now and forever'. Thus, in relation to the high climate scenario, including non-market impacts, where Stern, at page 157, shows annual costs of damage rising from around zero in 2000 to $3 \%$ in 2100 and $13.8 \%$ in 2200 (unweighted average value for the 200 years less than 5\%), Stern estimates total average cost 'now and forever' of $14.4 \%$. Whence the difference? The answer is provided in Stern's Box 6.3, which explains that the utility projections include an allowance for growth in consumption from the year 2200 to infinity. A substantial part of the assessed 'now and forever' cost lies beyond the year 2200 .

This contrast highlights the problems inherent in long-range inter-generational comparisons of welfare. Enjoying my eighth decade and knowing that my grandchildren will be interested in the welfare of their grandchildren, I naturally incline to a longer view. I also recall William Blake's musings on 'dark Satanic mills' in 'England's green and pleasant land' just 200 years ago. Nevertheless, realism suggests that when it comes to translating distant fears into practical actions now, it will be difficult to sustain consensus for action on the scale required.

For example, the calculations underlying Table 2 show that the posited $1.0 \%$ of GDP spent on mitigation will need to be sustained over long periods before the discounted benefits, in terms of avoided climate damage, begin to exceed the discounted cost of the mitigation programme. Even at a discount rate of $0.1 \%$, break-even is 93 years distant under the high climate scenario and 132 years distant under baseline. Adopt Green Book rules and these stretch out to 122 and 187 years respectively. These are long periods to sustain a policy, particularly when the benefits of such a policy will always depend on a comparison of what actually is with the unknowable counter-factual of what might otherwise have been.

\section{Setting a price on carbon}

A central message of the Stern Review is the urgent need to reduce greenhouse gas emissions, either by internalising the costs of emissions into the prices that we face when planning more or less greenhouse gas-intensive activities, or by regulation. The policy messages are that prices offer greater flexibility and are likely to be more efficient, but that they will need to be supplemented and indeed underwritten by regulation. 
To be effective, both price and regulatory regimes need to be international in scope.

These will be public policy choices of a high order. They will involve trade-offs between costs at different points in time. To be effective they will also need to emerge from an ongoing debate that clarifies the issues and builds sufficient common understanding of the trade-offs involved to enable public choice to be made, sustained and modified in the light of evolving circumstances and understandings.

The price of carbon provides an interesting illustration of the extent to which such choices are conditional on discounting assumptions.

Chapter 13 of the Stern Review, 'Towards a goal for climate-change policy', is concerned with establishing realistic targets for ultimate atmospheric concentrations of greenhouse gases, taking account of the trade-off between the costs of mitigation, which will be lower the less ambitious the target, and the costs of climate change, which will increase as the target is made less ambitious. Estimates of the cost of climate change and of mitigation are sensitive to discounting assumptions, as therefore is judgement on the implicit price of carbon emissions. Stern reviews the literature on estimates of the social cost of carbon and notes the sensitivity of such estimates to discounting assumptions.

In a 1996 article, William Nordhaus estimated that a shift from a $3 \%$ to a $1 \%$ discount rate would increase carbon taxes fourfold. He has now explored the sensitivity of carbon prices to discounting assumptions in model runs calibrated to match the Stern Review. Under a reference run of his DICE model using a $3 \%$ discount rate, the optimal carbon price is estimated at $\$ 17.12$ per ton $C$, in 2005 , rising to $\$ 84$ in 2050 and $\$ 270$ in 2100 . Substituting a $0.1 \%$ discount rate implies an optimal carbon price of $\$ 159$ per ton $\mathrm{C}$ in 2005 .

\section{Conclusion}

The Stern Review establishes a presumption in favour of strong collective action now but, at the same time, evidences ranges of uncertainty on many underlying facts and parameter values that will pose ongoing puzzles for researchers, policy makers and communities as they attempt to frame a response. Two concluding quotations are in order.
Nordhaus, in his 1996 paper, concluded:

[The] inherent difficulties involved in planning over a horizon of a century or more about so uncertain and complex a phenomenon are compounded by the dispersed nature of the decisions and the strong tendency for free-riding by nonparticipants in any global agreement. Countries may therefore be triply persuaded not to undertake costly efforts today - first because the benefits are so conjectural, secondly because they occur so far in the future, and third because no single country can have a significant impact upon the pace of global warming. (Nordhaus and Yang, 1996, p.763)

Stern, discussing the economics of stabilisation, comments:

Some of the parameters that modellers have treated as uncertain, such as discount factors and equity weights, reflect societies' preferences. In the process of agreeing an international stabilisation objective, or at least narrowing its range, discussions have to resolve, or at least reduce disagreement over, the issues of social choice lying behind these uncertainties. (Stern, p.292)

The long-standing academic disagreements on discount rates suggest that this necessary opening up of the professional debate into public forums, so that we can all agree on the price at which we should tax our greenhouse gas emissions, is likely to have its fractious moments. Bon appetit.

\section{References}

Alberth, S. and C. Hope (2005) 'Developing the PAGE2002 model with endogenous technical change', Judge Business School website, University of Cambridge

Blake, W. (1808-10) Preface to Milton

Broome, J. (2006) 'Valuing policies in response to climate change: some ethical issues', at www.hmtreasury.gov.uk

Carter, R.M. et al. (2006) 'The Stern Review: a dual critique world', Economics, 7 (4), October-December

Hepburn, C. (2006) 'Discounting climate change 
damages: working note for the Stern Review', at www. hm-treasury.gov.uk

Lind, R.C. (1990) 'Reassessing the government's discount rate policy in light of new theory and data in a world economy with a high degree of capital mobility', Journal of Environmental Economics and Management

New Zealand Treasury (2005) Cost Benefit Analysis Primer, at www.treasury.govt.nz/costbenefitanalysis/

Nordhaus, W. (2006) 'The Stern Review on the economics of climate change', 17 November, Yale University website

Nordhaus, W.D. and Z. Yang (1996) 'A Regional Dynamic General-Equilibrium model of alternative climate-change strategies', American Economic Review, 86 (4), September

Quiggin, J. (2005) 'Risk and discounting in project evaluation', appendix in Risk in Cost-Benefit Analysis, Bureau of Transport and Regional Economics report 110, Canberra: Bureau of Transport and Regional Economics

Spackman, M. (2004) 'Time discounting and the cost of capital in government', Fiscal Studies, 25 (4)

Stern, N. (2006) Stern Review on the Economics of Climate Change, at www.hm-treasury.gov.uk; see also the postscript, technical annex and note on frequently asked questions

Transfund New Zealand (2004) Project Evaluation Manual

United Kingdom Treasury (2003) The Green Book, at www.hm-treasury.gov.uk

References to Ramsey, Pigou and Solow are given in Hepburn (2006)

Dennis Rose is a research economist working in retirement. His current interests include the determinants of national interest rates and employment policy.
IMPLICATIONS OF POPULATION AGEING: Opportunities and Risks

An Institute of Policy Studies publication edited by Jonathan Boston and Judith $\mathrm{A}$. Davey

Population ageing, both globally and in New Zealand, is often seen in negative terms. But it can also be viewed positively - as an opportunity, an achievement of human civilisation and thus something to celebrate. The contributors to the 14 chapters in Implications of Population Ageing: Opportunities and Risks explore New Zealand's changing demography and examine many of the policy implications of population ageing, including those impinging on fiscal management, income support and the labour market.

The crucial message is that while population ageing undoubtedly poses serious challenges, it also generates many opportunities and possibilities, and the recognition of these will be critical for New Zealand's long-term economic and social success.

Published - October 2006

Format - B5 Paperback, pp 388

ISBN - 1-877347-14-0

Price - \$39.90 (incl P\&P within NZ)

To have a copy of Implications of Population Ageing: Opportunities and Risks and an invoice sent to you, please email, phone, fax or mail your order to

\section{Institute of Policy Studies}

Victoria University of Wellington

Email ipos@vuw.ac.nz

Telephone +64 44635307

Fax +64 44637413

P0 Box 600, Wellington

New Zealand 